\title{
OPTIMAL POSITION OF SOLAR COLLECTORS: A REVIEW
}

UDC: 523.9: 621.311.243

Review paper

https://doi.org/10.18485/aeletters.2018.3.4.3

\author{
Jasmina Skerlic ${ }^{1}$, Danijela Nikolic ${ }^{1}$, Dragan Cvetkovic ${ }^{1}$, Aleksandar Miškovic ${ }^{2}$ \\ ${ }^{1}$ University of Kragujevac, Faculty of Engineering, Kragujevac, Serbia \\ ${ }^{2}$ Technical College of Applied Studies, Kragujevac, Serbia
}

\begin{abstract}
:
Solar energy is the most abundant, inexhaustible and clean of all the renewable energy resources till today. Solar energy has received much more attention in building energy systems in recent years.

During the first years of the twenty-first century, extensive efforts have been undertaken to alleviate global warming of the earth caused by emission of $\mathrm{CO}_{2}$ in atmosphere. These emissions are generated by intensive burning of fossil fuels to satisfy the growing energy needs of humanity. The emissions may be mitigated when part of energy needs is satisfied by using non-polluting energy sources such as solar energy, instead of fossil fuels. In households, customary is to use electricity for heating of DHW. Most of electricity is produced by using coal with high greenhouse emission. Accordingly, worldwide, the most rewarding application of solar energy is when it replaces electrical energy for heating of DHW in households.

The solar collector has to take the optimal position that will guarantee the highest generation of heat. Optimal positioning must be based on rigorous calculations and not on the basis of experience. Such calculations lead to the improvement of the operation of solar energy systems. This paper gives a review of research with the objective of presenting, classifying and analysing the different criteria by which the authors observed an optimal position of the solar collector. In addition, it is important to have a high efficiency of conversion of solar energy to heat. Then, the highest amount of avoided primary energy, avoided electrical energy, avoided exergy, and decrease in $\mathrm{CO}_{2}$ emissions may be expected.
\end{abstract}

ARTICLE HISTORY

Received: 01.08.2018.

Accepted: 17.11.2018.

Available: 31.12.2018.

\section{KEYWORDS}

Domestic hot water, azimuth angle, tilt angle, orientation, optimization, simulation

\section{INTRODUCTION}

During the first years of the twenty- first century, extensive efforts have been undertaken to alleviate global warming of the earth caused by emission of $\mathrm{CO}_{2}$ in atmosphere. These emissions are generated by intensive burning of fossil fuels to satisfy the growing energy needs of humanity. The emissions may be mitigated when part of energy needs is satisfied by using non-polluting energy sources such as solar energy, instead of fossil fuels. Also, another important advantage of the usage of solar energy is that it does not pollute the environment with nitrogen oxides and sulfur dioxide.

In Serbian households, the high amount of DHW is used for shower, tap, cloths-washing machines, and dish-washing (machines). It is customary to use electricity for heating of DHW. As around $70 \%$ of electricity is produced by using coal with high greenhouse emission, it is important and the most rewarding to use solar energy for DHW heating instead of electrical energy. Accordingly, in Serbia and worldwide, the most rewarding application of solar energy is when it replaces electrical energy for heating of DHW in households [1]. In addition it is important to have a high 
efficiency of conversion of solar energy to heat. Then, the highest amount of avoided primary energy, avoided electrical energy, avoided exergy, and decrease in $\mathrm{CO}_{2}$ emissions may be expected.

The solar collector has to take the optimal position that will guarantee the highest generation of heat. This paper gives a review of research with the objective of presenting, classifying and analysing the different criteria by which the authors observed an optimal position of the solar collector.

Therefore, it is important to have a high efficiency of conversion of solar energy to heat. Then, the highest amount of avoided primary energy, avoided electrical energy, avoided exergy, and decrease in $\mathrm{CO}_{2}$ emissions may be expected. As studied by different authors [2-5], general rules of thumb can be stated for the installation of solar flat plate collectors. For maximum annual energy availability, the slope of the collector should be equal to the angle of latitude for low latitude countries $\left(\delta<40^{\circ}\right)$, increasing to latitude plus $10^{\circ}$ for higher latitude countries $\left(\delta>40^{\circ}\right)$. For a latitude of $45^{\circ} \mathrm{N}$, the variation of the total energy received $S$ a function of slope showed that the changes in total annual energy received are less than $5 \%$ for slopes of $20^{\circ}$ more or less than the optimum [6-8]. Calculations of total annual energy for $\delta=45^{\circ}$, for surfaces of slopes of $30^{\circ}$ and $60^{\circ}$, as a function of surface azimuth angle showed a small reduction in annual energy from the optimum (tilting towards the south). The generalization made in the literature was that the collectors facing $10-20^{\circ}$ east or west of south should make little difference in the annual energy received. These literatures are mostly concentrated on higher latitude countries.

\section{METODOLOLOGY}

The slope angle $(\beta)$ of any collector is defined as the angle between the plane of the collector and the horizontal. The azimuth angle $(X)$ is defined as the displacement angle between the projection on a horizontal plane of the normal to the collector surface and due north.

The incidence angle, $e$, is the angle between the direct radiation on a surface and the normal to that surface. For maximum direct radiation, the incidence angle should be a minimum. Fig.1 shows these angles.

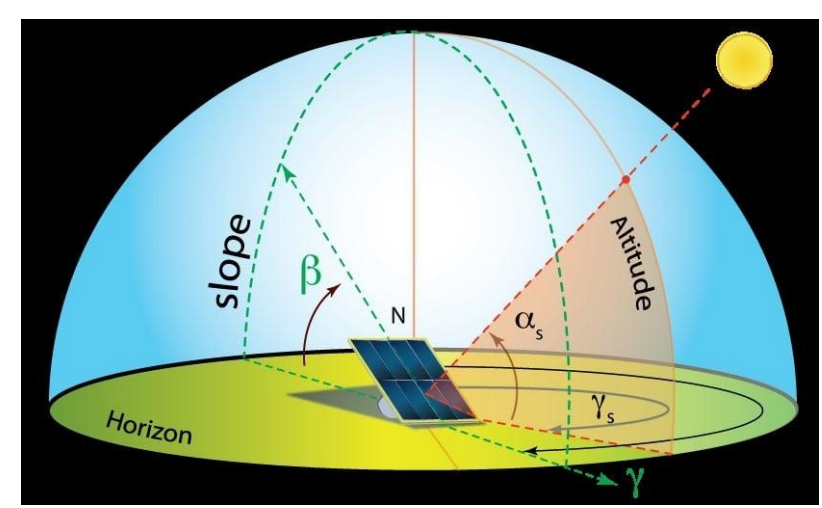

Fig. 1. Major angles in solar applications [9]

\section{OPTIMAL POSITION}

The orientation of a collector can be described with the help of its slope and azimuth angles. These two parameters can varied in special computer codes in order to find the optimal orientation.

\subsection{Optimal slopes}

The variation of annual diffuse, direct and total solar energy depends on slope angle. When slope angle is positive, the orientation of the surface is toward to the equator, and when is negative, the orientation is toward the pole. Bari [9] shows that the peak total occures at $60^{\circ}$ slope, corresponding to an azimuth angle of $180^{\circ}$. The peaks of the direct and diffused components are located on different slopes. The peak of the diffused component occurs at $0^{\circ}$, i. e. horizontal, whereas the paek of the direct component occurs at $60^{\circ}$.

\subsection{Optimum azimuth angle}

For maximum annual energy, the collectors should be tilted towards the equator, i. e. towads the south in the northern hemisphere and north in the southern hemisphere. At lqbal [8], when the slope is optimum variation of surface azimuth angle does not have significant effect on the received solar energy. Therefore, for low latitude countries, the collectors' azimuth angle can be oriented in any direction provided the tilt angle is optimum. For higher latitude countries, this night not be trued.

\section{SUMMARY OF CRITERIA}

During operation, solar collector has to take the optimal position that will guarantee the highest 
generation of heat. The solar collector takes the north-south direction and the objective is to find the optimum solar collector tilt. In literature, there is a lot of research with this objective. Based on the extraterrestrial solar radiation, Gunerhan and Hepbasli determined the monthly optimum orientation and tilt angles of solar collectors Bopt equal to latitude $\phi$ throughout the year at Izmir, Turkey and suggest, while for summer $\beta=\phi-15$ opt and for winter $\beta=\phi+15$ opt [10], and Chang calculated the optimal tilt angle of a solar collector in the northern hemisphere [11]. By using the equations for the global solar radiation by an empirical model, Nijegorodov and Jain calculated optimum slope of a north-south aligned absorber plate from the north to the south poles [12], Chang calculated the optimal tilt angle of a solar collector in the northern hemisphere [11], and Moncos calculated the optimum tilt angle for solar collectors in Assiut, Egypt [13]. By determining the sunshine duration. Based on the incident angles of the direct solar radiation, Skeiker (2009) Presented a mathematical model to compute the optimum tilt angle and orientation (surface azimuth angle) of solar collector Syrian zones and recommend that by changing the tilt angle 12 times in a year and found the solar radiation approximately is the maximum data [14]. By taking into account position of the sun at the sky and using the model of ASHRAE, Bari calculated the optimum orientation of domestic solar collectors for the low latitude countries [9]. Bari proposed a polynomial equation of six order for calculating the optimum tilt angle (ßopt) for different latitudes in the Thailand territory [15]. Bari showed a method to determine the optimum tilt angle and orientation of solar collectors to utilize both the direct and diffuse components of solar radiation for different periods of operation at latitudes $1^{\circ}, 3^{\circ}, 5^{\circ}$ and $7^{\circ}$ in the Malaysian territory [16]. Hussein developed theoretically, analysis of the instantaneous, daily, and yearly solar energy collection of a tilted flatplate solar collector augmented by a plane reflector [17]. Tiris, M., \& Tiris, C. Discussed the optimal tilt angle and orientation of south-facing solar collector in different regions, and found the optimum tilt depends upon the latitude and the day of the year [18]. By using the measured values of the global solar radiation, Ibrahim calculated the optimum tilt angle for solar collectors used in Cyprus [19]. By searching for values for maximum of the total radiation for a specific period by using measured data for global and diffuse radiation, Yakup and Malik calculated the optimum tilt angle and orientation for solar collector in Brunei Darussalam [20]. Based on the measured monthly average incident solar radiation, Hartley et al. calculated optimized the angle of inclination of a solar collector [21]. Based on the monthly horizontal radiation, Tang and $\mathrm{Wu}$ developed a method to estimate the optimal tilt angles of a solar collector based on the monthly horizontal radiation and prepared a map showing optimal tilt angles for the year for south facing collectors in China [22]. Cheng investigated the correlation between the tilt angle of a fixed solar collector and the latitude using the simulation software PVSYST at 20 locations in 14 countries on the northern hemisphere and found there are increase of $98.5 \%$ for a solar power plant from its full capacity by using the latitude angle for the tilted panel [23]. Based on the measured data for solar radiation by meteorological station, Shariah et al. optimized the tilt angle of solar collectors for the SDHW system where maximum solar fraction was used as an indicator for the optimum tilt angle [24] which is the case in the presented investigations [25], Skerlic reported an investigation of the energy performance for variable tilt lat- plate solar collectors in Belgrade, Serbia. The investigated solar collectors are SC\#2, SC\#4, and SC\#12. These solar collectors are placed at roofs of houses in north-south direction. The used weather data were from the meteorological station. These investigations use computer codes in EnergyPlus and GenOpt software with the application of Hooke-Jeeves search algorithm. For the different variable tilt SCs, the investigations yield their optimum tilts that maximize the solar fraction, avoided electricity, and avoided fossil energy by the SDHWS. In addition the research will study the deficit in the solar fraction when the tilt in practice is not optimal. After that the values of the avoided electricity are compared for all cases in order to show the real need for SC\#2, SC\#4, and SC\#12 in practice [26]. Talebizadeh, reported investigation, the optimum slope and azimuth angles for hourly, daily, monthly, seasonally and yearly bases were found using the Genetic Algorithm (GA) respectively. The percentages of heat gain of a solar collector under these optimum angles were obtained. Furthermore, the importance of solar radiation components on the performance of solar collectors and photovoltaic panels were investigated by predicting the optimum slope angle and the input solar energy in different combinations of the solar components [27]. Bracamonte et al. showed effect of the tilt angle 
$\left(10^{\circ}, 27^{\circ}\right.$ and $\left.45^{\circ}\right)$ on thermal efficiency and stratification of water in glass evacuated tube passive solar water heater [28]. Manouchehri et al. presented impact of small tilt angles of $0^{\circ}, 2^{\circ}, 5^{\circ}$, $10^{\circ}$ and $15^{\circ}$ with respect to the vertical on the performance of falling film drain water heat recovery systems [29]. Tang investigated the thermal performance of the water in glass evacuated tube in the solar water heaters (SWH) at nights where the larger the tilt-angle of the collector lead to increase the reverse flow rate [30]. Zhang showed that the tilt angle did not affect on the performance of the solar water heaters at china [31]. Tang showed the performance for two identical solar water heaters in the design under various collector tilt-angle from the horizon by $22^{\circ}$ and the other one at $46^{\circ}$. Jafarkazemi and Saadabadi investigated the effect of the optimum tilt angle and orientation of PV panels and solar collectors by change the tilt angle, at least twice a year in Abu Dhabi, UAE [32]. Khorasanizadeh et al. (2014) Calculated the optimum tilt angle of southfacing solar surfaces in Tabass, Iran, for the monthly, seasonal, semi-yearly and yearly where the monthly optimum tilt varies from $0^{\circ}$ in June and July up to $64^{\circ}$ in December and the yearly optimum tilt is around $32^{\circ}$, which is very close to latitude of Tabass $\left(33.36^{\circ}\right)$. The semi-yearly tilt adjustment of $0^{\circ}$ for (April-September) and $55^{\circ}$ for (October-March) was preferred [33]. Patkó et al. (2013) Determined theoretically the optimal tilt angle of sun collectors for the four seasons (autumn, winter, spring, summer) [34]. Gitan developed a mathematical model to estimate the performance of (SUPP) based on tracking solar collector consideration and optimize the slope angle of tilted tracking solar collector in Malaysia [35]. Stanciu, C., and Stanciu, D. proposed a numerical simulation of a flat plate collector for the optimum tilt angle at different latitudes from $0^{\circ}$ to $80^{\circ}$ as $\beta=\phi-\delta$ opt function on the latitude $(\varphi)$ and solar declination ( $\delta),[36]$. Moghadam and Deymeh determined the optimum location and optimum tilt angle of solar collectors on the roof, with respect to the shadow of adjacent buildings [37]. Rahman investigated a range of tilt angles from 0 to $60^{\circ}$ on a solar collector, which is an important factor and the heat transfer, can be maximized for solid volume fraction of the nanofluid and a specific tilt angle [38]. Handoyo and Ichsani obtained the optimal tilt angle of a solar collector to maximize the solar radiation received at Surabaya - Indonesia and found the optimal tilt angle during March 12 - September 30 is varied between 0 and $40^{\circ}$ (face to the North) and during October 1 - March 11 is between 0 and $30^{\circ}$ (face to the South) [39]. Moghadam performed an optimization of solar flat collector inclination to determine monthly, seasonal, semi-annual and annual optimum tilt angles [40].

\section{CONCLUSION}

The performance of solar water systems not only depends on the solar energy absorbed by the collector, but it also depends on factors such as thermal energy lost from the collector to the surroundings by conduction, convection and infrared radiation, tube spacing inside the collector, the geometry of the collector, material properties etc. However, one of the criteria to improve the efficiency of the collector is to increase the absorbed radiation by the collector [2-4], which emphasizes the importance of proper orientation of the collector.

For value for money, the collector should be oriented properly so as to receive maximum solar radiation. A survey conducted in many cantries in world showed that almost all the collectors are not properly installed. They are mounted on the roof, so the roof's slope is the slope of the collector and the roof's azimuth angle is the collector's azimuth angle.

A computer program, developed to investigate the effect of slope and azimuth angle of the collector on the annual energy received, showed that the average loss of energy of these collectors is $10-35 \%$. In some cases, the loss is as high as $50 \%$. This clearly indicates lack of knowledge of both the suppliers and the consumers in this field.

\section{ACKNOWLEDGEMENT}

This paper is a result of the projects TR33015 which is financed by the Ministry of Education, Science and Technological Development of Republic of Serbia. The authors thank to this institution for its financial support.

\section{REFERENCES}

[1] T.M. Razykov, C.S. Ferekides, D. Morel, E. Stefanakos, H.S. Ullal, H.M. Upadhyaya, Solar photovoltaic electricity: Current status and future prospects. Solar Energy 85 (-), 2011: 1580-1608.

https://doi.org/doi:10.1016/i.solener.2010.12.002 
[2] J.A. Duffie, W.A. Beckman, Solar engineering of thermal processes. Wiley, New York, 1991, p.13-19.

[3] J.A. Duffie, W.A. Beckman, Solar engineering of thermal processes, Wiley, New York, 1991, p.91-94.

[4] P.D. Dunn, Renewable energies: sources, conversion and application, Cambridge: Heffers Printers, 1986, p.174-175.

[5] R.N. Morse, J.T. Czarnecki, Flat plate absorbers: the effect of incident radiation on inclination and orientation. Solar Energy, 4 (4), 1960: 40-41.

https://doi.org/10.1016/0038-092X(60)90010-4

[6] Report E.E., 6 of Engineering Section, Commonwealth Scientific and Industrial Research Organization, Melbourne, Australia, 1958.

[7] R.C. Temps, K.L. Coulson, Solar radiation incident upon slopes of different orientations. Solar Energy, 19 (2), 1977: 179-184.

https://doi.org/10.1016/0038-092X(77)90056-1

[8] C.C.Y. Ma, M. Iqbal, Statistical comparison of models for estimating solar radiation on tilted surfaces. Solar Energy, 31 (3), 1983: 313-317.

https://doi.org/10.1016/0038-092X(83)90019-1

[9] S. Bari, Optimum orientation of domestic solar water heaters for the low latitude countries. Energy Conversion and Management, 42 (10), 2001: 1205-1214.

https://doi.org/10.1016/S0196-8904(00)00135-7

[10] H. Gunerhan, A, Hepbasli, Determination of the optimum tilt angle of solar collectors for building applications. Building and Environment, 42 (2), 2007: 779-783.

https://doi.org/10.1016/i.buildenv.2005.09.012

[11] T.P. Chang, The Sun's apparent position and the optimal tilt angle of a solar collector in the northern hemisphere. Solar Energy, 83 (8), 2009: 1274-1284.

https://doi.org/10.1016/i.solener.2009.02.009

[12] N. Nijegorodov, P.K. Jain, Optimum slope of a north-south aligned absorber plate from the north to the south poles. Renewable Energy, 11 (1), 1997: 107-118.

https://doi.org/10.1016/S0960-1481(96)00112-7

[13] V.H. Morcos, Optimum tilt angle and orientation for solar collectors in Assiut, Egypt. Renewable Energy, 4 (3), 1994: 291298.

https://doi.org/10.1016/0960-1481(94)90032-9

[14] K. Skeiker, Optimum tilt angle and orientation for solar collectors in Syria. Energy Conversion and Management, 50 (9), 2009: 2439-2448.

https://doi.org/10.1016/i.enconman.2009.05.031
[15] S. Bari, T.H. Lim, C.W. Yu, Slope angle for seasonal applications of solar collectors in Thailand. International Energy Journal, 2 (1), 2001: 43-51.

[16] S. Bari, Optimum slope angle and orientation of solar collectors for different periods of possible utilization. Energy Conversion \& Management, 41 (8), 2000: 855-860.

[17] H.M.S. Hussein, G.E. Ahmad, M.A. Mohamad, Optimization of operational and design parameters of plane reflector-tilted flat plate solar collector systems. Energy, 25 (6), 2000: 529-542.

https://doi.org/10.1016/50360-5442(00)00003-7

[18] M. Tiris, C. Tiris, Optimum collector slope and model evaluation: case study for Gebze, Turkey. Energy Conversion and Management, 39 (3-4), 1998: 167-172.

https://doi.org/10.1016/S0196-8904(96)00229-4

[19] D. Ibrahim, Optimum tilt angle for solar collectors used in Cyprus. Renewable Energy, 6 (7), 1995: 813-819.

https://doi.org/10.1016/0960-1481(95)00070-Z

[20] Mohd Azmi bin Hj Mohd Yakup, A.Q. Malik, Optimum tilt angle and orientation for solar collector in Brunei Darussalam. Renewable Energy, 24 (-), 2001: 223-234.

https://doi.org/10.1016/S0960-1481(00)00168-3

[21] L.E. Hartley, J.A. Martinez-Lozano, M.P. Utrillas, S.F. Tena, E.R. Pedros, The optimisation of the angle of inclination of a solar collector to maximise the incident solar radiation. Renewable Energy, 17 (-), 1999: 291-309.

https://doi.org/10.1016/50960-1481(98)00763-0

[22] R. Tang, T. Wu, Optimal tilt-angles for solar collectors used in China. Applied Energy, 79 (3), 2004: 239-248.

https://doi.org/10.1016/j.apenergy.2004.01.003

[23] C.L. Cheng, C.S.S. Jimenez, M.C. Lee, Research of BIPV optimal tilted angle, use of latitude concept for south orientated plans. Renewable Energy, 34 (6), 2009: 1644-1650.

https://doi.org/10.1016/j.renene.2008.10.025

[24] A. Shariah, M.A. Al-Akhras, I.A. Al-Omari, Optimizing the tilt angle of solar collectors. Renewable Energy, 26 (4), 2002: 587-598.

https://doi.org/10.1016/50960-1481(01)00106-9

[25] J. Skerlić, J. Radulović, D. Nikolić, M. Bojić, Maximizing performances of variable tilt flatplate solar collectors for Belgrade (Serbia). Journal of Renewable and Sustainable Energy, 5 (041820), 2013: 1-15.

https://doi.org/10.1063/1.4819254 
[26] P. Talebizadeha, M.A. Mehrabiana, M. Abdolzadeh, Prediction of the optimum slope and surface azimuth angles using the Genetic Algorithm. Energy and Buildings, 43 (11), 2011: 2998-3005.

https://doi.org/10.1016/i.enbuild.2011.07.013

[27] J. Bracamonte, J. Parada, J. Dimas, M. Baritto, Effect of the collector tilt angle on thermal efficiency and stratification of passive water in glass evacuated tube solar water heater. Applied Energy, 155 (-), 2015: 648-659.

https://doi.org/10.1016/j.apenergy.2015.06.008

[28] R. Manouchehri, C.J. Banister, M.R. Collins, Impact of small tilt angles on the performance of falling film drain water heat recovery systems. Energy and Buildings, 102 (-), 2015: 181-186.

https://doi.org/10.1016/i.enbuild.2015.05.024

[29] R. Tang, Y. Yang, Nocturnal reverse flow in water-in-glass evacuated tube solar water heaters. Energy Conversion and Management, $80(-), 2014:$ 173-177.

https://doi.org/10.1016/j.enconman.2014.01.025

[30] X. Zhang, S. You, W. Xu, M. Wang, T. He, X. Zheng, Experimental investigation of the higher coefficient of thermal performance for water-in-glass evacuated tube solar water heaters in China. Energy Conversion and Management, 78 (-), 2014: 386-392.

https://doi.org/10.1016/i.enconman.2013.10.070

[31] R. Tang, Y. Yang, W. Gao, Comparative studies on thermal performance of water-in glass evacuated tube solar water heaters with different collector tilt-angles. Sol Energy, 85 (7), 2011: 1381-1389.

https://doi.org/10.1016/i.solener.2011.03.019

[32] F. Jafarkazemi, S.A. Saadabadi, Optimum tilt angle and orientation of solar surfaces in Abu Dhabi. Renewable Energy, 56 (-), 2013: 44-49.

https://doi.org/10.1016/i.renene.2012.10.036

[33] H. Khorasanizadeh, K. Mohammadi, A. Mostafaeipour, Establishing a diffuse solar radiation model for determining the optimum tilt angle of solar surfaces in Tabass, Iran. Energy Conversion and Management, 78 (-), 2014: 805-814.

https://doi.org/10.1016/i.enconman.2013.11.048

[34] I. Patkó, A. Szeder, C. Patkó, Evaluation the impact tilt angle on the sun collectors. Energy Procedia, 32 (-), 2013: 222-231.

https://doi.org/10.1016/i.egypro.2013.05.029

[35] A.A. Gitan, S.H. Abdulmalek, S.S. Dihrab, Tracking collector consideration of tilted collector solar updraft tower power plant under Malaysia climate conditions. Energy, 93 $(-), 2015:$ 1467-1477.

https://doi.org/10.1016/i.energy.2015.09.009

[36] C. Stanciu, D. Stanciu, Optimum tilt angle for flat plate collectors all over the World-A declination dependence formula and comparisons of three solar radiation models. Energy Conversion and Management, 81 (-), 2014: 133-143.

https://doi.org/10.1016/i.enconman.2014.02.016

[37] H. Moghadam, S.M. Deymeh, Determination of optimum location and tilt angle of solar collector on the roof of buildings with regard to shadow of adjacent neighbors. Sustainable Cities and Society, 14 (-), 2015: 215-222.

https://doi.org/10.1016/i.scs.2014.09.009

[38] M.M. Rahman, S. Mojumder, S. Saha, S. Mekhilef, R. Saidur, Effect of solid volume fraction and tilt angle in a quarter circular solar thermal collectors filled with CNT-water nanofluid. International Communications in Heat and Mass Transfer, 57 (-), 2014: 79-90.

https://doi.org/10.1016/i.icheatmasstransfer.2014.07.005

[39] E.A. Handoyo, D. Ichsani, Prabowo, The optimal tilt angle of a solar collector. Energy Procedia, 32 (-), 2013: 166-175.

https://doi.org/10.1016/j.egypro.2013.05.022

[40] H. Moghadam, F.F. Tabrizi, A.Z. Sharak, Optimization of solar flat collector inclination. Desalination, 265 (1-3), 2011: 107-111.

https://doi.org/10.1016/i.desal.2010.07.039 